Revista de Economia Política, vol. 20, $n^{\circ} 2$ (78), pp. 242-266, abril-junho/2000

\title{
O Modelo de Racionamento de Crédito e a Política Monetária Novo-Keynesiana: Uma Análise Crítica*
}

\author{
The Credit Rationing Model and the Novo-Keynesian \\ Monetary Policy: A Critical Analysis
}

JENNIFER HERMANN***

RESUMO: O artigo discute e critica o modelo de racionamento de crédito (CRM) e seu uso para apoiar a abordagem nova-Keynesiana da política monetária. Após analisar o funcionamento do modelo nas diferentes fases do ciclo de negócios, conclui-se que: (i) na fase ascendente, o equilíbrio do racionamento da demanda — que é uma condição para a recomendação da política monetária anticíclica no âmbito do CRM - não é plausível como um fenômeno macroeconômico, mas apenas no nível microeconômico; (ii) na fase descendente, embora o racionamento da demanda seja um equilíbrio plausível, não ocorre pela razão alegada pelo CRM (rigidez da taxa de juros), nem atua a favor do mecanismo de transmissão da política monetária. Essas conclusões implicam a rejeição do CRM como base teórica para a análise da política monetária, bem como da nova abordagem Keynesiana sobre esse tema. Finalmente, argumenta-se que, no nível macroeconômico, a contribuição teórica única do CRM é justificar intervenções “verticais” do governo nos mercados financeiros, por meio de políticas de financiamento para setores ou projetos cujos riscos são mais difíceis de estimar, notadamente, em infraestrutura. setores de infraestrutura, P\&D e novas tecnologias.

PALAVRAS-CHAVE: Modelo de racionamento de crédito; política monetária; política anticíclica; mercado de crédito.

ABSTRACT: The paper discusses and criticizes the credit rationing model (CRM) and its use to support the new-Keynesian approach to the monetary policy. After analyzing the working of the model in the different phases of the business cycle it is concluded that: (i) in the upward phase, demand rationing equilibrium - which is a condition for recommendation of counter-cyclical monetary policy in the CRM scope - is not plausible as a macroeconomic phenomenon, but only at microeconomic level; (ii) in the downward phase, although the demand rationing is a plausible equilibrium, it does not occur for the reason alleged by

\footnotetext{
* Este artigo faz parte do Projeto de Estudos da Moeda e do Sistema Financeiro, desenvolvido no Instituto de Economia da Universidade Federal do Rio de Janeiro (IE/UFRJ), com apoio do CNPq.

* Professora e pesquisadora do Instituto de Economia da Universidade Federal do Rio de Janeiro - IE-UFRJ, Rio de Janeiro/RJ, Brasil. E-mail: jenniferh@terra.com.br.
} 
the CRM (the rigidity of the interest rate), neither it does act in favour of the transmission mechanism of monetary policy. These conclusions imply the rejection of the CRM as theoretical basis for monetary policy analysis, as well as of the new-Keynesian approach about this theme. Finally, it is argued that, at macroeconomic level, the unique theoretical contribution of the CRM is to justify "vertical" interventions of government in financial markets, through financing policies to sectors or projects which risks are more difficult to estimate, notably, in infra-structure, R\&D and new-technology sectors.

KEYWORDS: Credit rationing model; monetary policy; countercyclical policy; credit market. JEL Classification: E12; G21; G31.

\section{INTRODUÇÃO}

O modelo de racionamento de crédito, cuja sistematização mais completa é devida a Stiglitz \& Weiss (1989) tados da abordagem novo-keynesiana na área da política monetária, quais sejam: (i) que a atuação anticíclica da autoridade monetária é eficaz e recomendável em economias sob desemprego; (ii) que o mecanismo de transmissão da política monetária não passa, como sustentaram os "antigos" keynesianos, pela flexibilidade da taxa de juros - ao contrário, a transmissão se explica pela rigidez da taxa de juros e pela resposta direta da oferta de crédito bancário.

Tanto a eficácia quanto o modo de operação da política monetária são justificados, no modelo, com base na tese de que, em virtude da assimetria de informação que lhe é característica, o mercado de crédito opera de forma não-walrasiana, isto é, com preço $(\mathrm{r})$ rígido e quantidade $(\mathrm{L})$ determinada pela regra de mínimo: $\mathrm{L}$ $=\min \{\mathrm{Ls}, \mathrm{Ld}\}$, onde $\mathrm{Ls}=$ oferta de fundos emprestáveis e $\mathrm{Ld}=$ demanda por fundos emprestáveis. A política monetária expansiva, então, seria recomendada sempre que o equilíbrio do mercado fosse do tipo $\mathrm{L}=\mathrm{Ls}<\mathrm{Ld}$, o que caracteriza um equilíbrio com racionamento de demanda. A partir desse esquema geral, a abordagem novo-keynesiana do mercado de crédito consiste, basicamente, na exploração de fundamentos microeconômicos que permitem ancorar sua tendência ao equilíbrio com racionamento de demanda na racionalidade dos agentes (mais especificamente dos bancos).

O presente texto faz uma análise crítica do modelo de racionamento de crédito (MRC) novo-keynesiano, questionando sua adequação como instrumento teórico de interpretação do papel dos bancos na dinâmica da economia, bem como do papel e do processo de transmissão da política monetária. Além da dificuldade empírica de se identificar a existência e magnitude da demanda racionada e, por conseguinte, a necessidade da intervenção expansiva do banco central, o MRC envolve algumas dificuldades de ordem teórica, relacionadas à hipótese de racio-

\footnotetext{
${ }^{1} \mathrm{O}$ referido artigo foi originalmente publicado em 1981, na American Economic Review, 71, June, pp. 353-376. As referências aqui mencionadas, porém, são as da edição de 1989.
} 
namento como expressão do comportamento racional/maximizador dos bancos. A crítica apoia-se em três argumentos centrais: (i) o equilíbrio com racionamento, tal como descrito no MRC, implica hipóteses pouco plausíveis sobre a conduta dos bancos nas diferentes fases dos ciclos econômicos; (ii) o equilíbrio com racionamento da demanda não se sustenta como fenômeno macroeconômico - o que descaracteriza o MRC como instrumento teórico adequado à análise da política monetária, que é, indiscutivelmente, uma questão de caráter macroeconômico; (iii) faltam elementos ao MRC para explicar o modo de operação da política monetária, cujo mecanismo de transmissão não pode ser entendido sem referência a seus efeitos sobre os custos do passivo bancário.

O artigo está organizado em quatro seções. A seção 1 descreve, sumariamente, as características gerais da abordagem novo-keynesiana e específicas do MRC. A seção 2 desenvolve as críticas (i) e (ii) acima mencionadas e, na seção 3, discute-se a crítica relacionada à política monetária. A seção 4 sumaria e conclui a discussão.

\section{O MODELO NOVO-KEYNESIANO DE RACIONAMENTO DE CRÉDITO}

\subsection{O MRC no Pensamento Novo-Keynesiano}

A escola novo-keynesiana surgiu no debate macroeconômico, no final dos anos 70, como reação ao movimento de reafirmação do pensamento neoclássico, iniciado por M. Friedman (1968, 1970 e 1976) e, mais tarde, liderado pelos novosclássicos. A partir da recuperação e sofisticação de modelos de equilíbrio geral walrasiano aplicados à análise da oferta agregada, o neoclassicismo na versão novo-clássica propugnou a falência da política econômica "ativista" inspirada na Teoria Geral de Keynes (1985) e nas diversas leituras (simpatizantes) dessa obra².

A reação novo-keynesiana consistiu, basicamente, no desenvolvimento de modelos do tipo supply side economics - nesse ponto, em perfeita sintonia com a abordagem novo-clássica —, nos quais, por força de diversos tipos de imperfeições dos mercados, o equilíbrio walrasiano não se verifica ou, pelo menos, não é a norma. Nessa visão, não só os preços são rígidos e, como tal, não atuam como instrumento comum de market clearing - seja no curto ou no longo prazo como o próprio market clearing torna-se questionável, sendo admitidas situações de equilíbrio com racionamento, do lado da oferta ou da demanda ${ }^{3}$. O desemprego keynesiano (involuntário) seria um exemplo típico de equilíbrio com racionamento da oferta (oferta planejada > oferta/demanda efetivas), enquanto o MRC ilustraria um caso de equilíbrio com racionamento da demanda (demanda planejada $>$ oferta/demanda efetivas).

\footnotetext{
${ }^{2}$ Ver, por exemplo, Lucas (1981), Lucas \& Sargent (1981), Sargent \& Wallace (1981) e Sargent (1981).

${ }^{3}$ Para uma síntese dos princípios da escola novo-keynesiana e de seu debate com os novos-clássicos, ver Mankiw (1990) e Mankiw \& Romer, (1989), Introdução.
} 
O reconhecimento da possibilidade de rigidez de preços e racionamento, contudo, não era suficiente para justificar a rejeição ao modelo teórico neo walrasiano, bem como à suas implicações de política econômica. Era necessário ainda "provar" que tais situações eram comuns em mercados relevantes (estratégicos) e que eram fruto da racionalidade dos agentes - e não de restrições exógenas ao perfeito funcionamento do (então correto) modelo walrasiano. Na supply side economics, mercados estratégicos são aqueles que determinam, direta ou indiretamente, as condições de custo (preços dos fatores) e disponibilidade de recursos alocáveis à produção (dotação de fatores). Assim, além do mercado de bens em geral, o programa de pesquisa novo-keynesiano voltou-se para o estudo dos mercados de trabalho e crédito - pela sua importância, respectivamente, na determinação daquelas duas condições. Os modelos de "menu costs", "salários de eficiência", "stagge red wages" (ajuste não sincronizado de salários) e "contratos a longo prazo" ilustram algumas das explicações dessa abordagem para a racionalidade da rigidez de preços - e do equilíbrio com racionamento da oferta - no mercado de trabalho. O MRC cumpre a mesma função no mercado de empréstimos bancários.

Modelos de equilíbrio geral com racionamento não são uma criação novokeynesiana, tendo sido antes propostos por outros autores da vertente keynesiana ${ }^{4}$. Contudo, enquanto estes se dedicaram, essencialmente, à questão teórica de demonstrar as condições de ocorrência do equilíbrio com desemprego, os novos-keynesianos se preocuparam, além disso, com a questão pragmática de firmar as condições de eficácia das políticas ativistas. Assim, uma diferença importante entre as antigas versões de equilíbrio com racionamento e a versão novo-keynesiana é que as primeiras enfatizaram a rigidez de preços à baixa - tal como Keynes na Teoria Geral - enquanto a segunda explora a racionalidade e consequências da rigidez ou "viscosidade" (ajuste lento) dos preços no sentido ascendente.

A hipótese de rigidez de preços à alta complementa o argumento novo-keynesiano a favor das políticas ativistas, sugerindo que o choque (positivo) de demanda por elas provocado não seria, em regra, compensado por majoração de preços nem no longo prazo, como sugere Friedman (1968 e 1976), nem no curto, como sustentam os novos-clássicos. O argumento novo-keynesiano passa, então, pela demonstração de que, diante de choques expansivas de demanda (por via fiscal ou monetária), os preços não reagem "walrasianamente" — leia-se: não sobem, anulando o "efeito liquidez real" da expansão ${ }^{5}$. Uma vez demonstrada a tendência dos mercados de fatores à rigidez de preços e ao equilíbrio com racionamento, a políti-

\footnotetext{
${ }^{4}$ Ver, por exemplo, Clower (1965), Malinvaud (1977), Leijonhufvud (1968) e (1981a).

${ }^{5} \mathrm{~A}$ rigidez de preços à alta é crucial ao alcance do resultado novo-keynesiano em relação à política anticíclica expansiva. Nota-se que a rigidez à baixa é capaz de justificar a desejabilidade da política ativista, mas não garante sua eficácia pelo efeito liquidez real. Se a expansão da renda nominal for acompanhada de aumento de preços, o aumento líquido na renda real pode ser nulo ou negligível. Enfim, em modelos walrasianos, se a restrição orçamentária da economia (sua "dotação de fatores") e/ou os preços relativos não se alteram (o que ocorreria se todos os preços subissem/pari passu com a expansão nominal da demanda), não há possibilidade de mudanças no nível de produção (ou de "utilidade" obtida
} 
ca expansiva torna-se defensável como instrumento capaz de remover ou, pelo menos, atenuar a restrição orçamentária dos agentes racionados.

O MRC é um exemplo típico da metodologia de análise novo-keynesiana. O modelo explica a participação do mercado de crédito bancário na criação endógena de restrições ao pleno emprego, com base na hipótese de equilíbrio com racionamento da demanda - o que justifica a conveniência da política monetária anticíclica. Seguindo a mecânica de ajuste de mercado acima descrita, a eficácia da política seria garantida pela rigidez dos juros à alta, mesmo na presença de estímulos positivos de demanda. Os aspectos microeconômicos do modelo são descritos a seguir.

\subsection{Fundamentos Microeconômicos do MRC}

No plano microeconômico, o ponto de partida do MRC é a observação de que os empréstimos bancários são operações condicionadas pela assimetria de informação, com os bancos na posição desfavorável — ou seja, negociando com menor grau de conhecimento sobre a real capacidade de pagamento do empréstimo pelo potencial devedor do que ele próprio ${ }^{6}$. Nesse contexto, a oferta de crédito (Ls) não é definida apenas em função do retorno esperado pelo banco, mas deste retorno ajustado ao risco.

O modelo admite as seguintes hipóteses simplificadoras: a) os projetos de investimento das firmas, que dão origem à demanda por empréstimos, são indivisíveis, no valor $\mathrm{K}$; b) todas as firmas têm recursos próprios no valor $\mathrm{W}<\mathrm{K}$, de modo que os empréstimos requeridos tenham valor, também indivisível, de $\mathrm{B}=(\mathrm{K}-\mathrm{W})$, igual para todas as firmas; c) os empréstimos são do tipo "não-amortizado", com um único pagamento de principal (B) e juros (r) ao final do período. ${ }^{7}$

De acordo com essas hipóteses, o retorno bruto do banco em cada empréstimo é dado, em princípio, por $(1+\mathrm{r})$ B. Tal valor, porém, só será obtido em caso de sucesso do empreendimento da firma tomadora, ao qual se atribui uma probabilidade Pi' no qual admite-se que a firma obtenha um retorno bruto de $S,>(1+r) B$. O risco do banco é, então, medido pela probabilidade de fracasso da firma, (1-P,), caso em que o pagamento será $\mathrm{F}<(1+\mathrm{r}) \mathrm{B}$. Assim, para cada projeto de financiamento, o retorno bruto esperado pelo banco é:

(1) $\mathrm{E}\left(\mathrm{Rb}_{\mathrm{i}}\right)=\mathrm{P}_{\mathrm{i}}[(1+\mathrm{r}) \cdot \mathrm{B}]+\left(1-\mathrm{P}_{\mathrm{i}}\right) \cdot \mathrm{F}$

Teoricamente, $0 \leq . \mathrm{P}_{\mathrm{i}} \leq 1$. Contudo, admitindo-se que não existam projetos de investimento sem risco (com $\mathrm{Pi}=1)$, nem totalmente arriscados $(\mathrm{Pi}=0)$, assume-se

da alocação de fatores). Assim, apenas a demonstração da rigidez de preços à alta, na presença de estímulos de demanda, é capaz de sustentar a tese da eficácia "real" da política expansiva.

${ }^{6} \mathrm{Na}$ abordagem novo-keynesiana, a assimetria de informação surge, basicamente, pelo fato de que a obtenção de informações detalhadas pelo banco envolve custos e pela impossibilidade de o banco monitorar o projeto de investimento que está financiando.

${ }^{7}$ A formalização apresentada nesta seção apoia-se em Blanchard \& Fisher (1994), cap. 9, pp. 480-484. 
$0<\mathrm{P}_{\mathrm{i}}<\mathrm{P}$, onde $\mathrm{P}$ representa a maior probabilidade de sucesso com que o banco trabalha, sendo $0<\mathrm{P}<1$. Analogamente, $(1-\mathrm{P})$ define o grau mínimo de risco do banco a cada período. Para o "contínuo de projetos" (como assume o modelo) considerados pelo banco, seu retorno esperado é dado por:

$$
\mathrm{E}(\mathrm{Rb})=[(1+\mathrm{r}) \cdot \mathrm{B}] \int_{0}^{\mathrm{p}} \mathrm{P}_{\mathrm{i}} \mathrm{g}\left(\mathrm{P}_{\mathrm{i}}\right) \mathrm{d} \mathrm{P}_{\mathrm{i}}+\mathrm{F} \cdot \int_{0}^{\mathrm{p}}\left(1-\mathrm{P}_{\mathrm{i}}\right) \mathrm{g}\left(\mathrm{P}_{\mathrm{i}}\right) \mathrm{d} \mathrm{P}_{\mathrm{i}} \text {, onde: }
$$

$\mathrm{g}\left(\mathrm{P}_{\mathrm{i}}\right)=$ função densidade das probabilidades de sucesso $P_{\mathrm{i}}$

Dados B e F, que são fixos e iguais para todas as firmas, de (2) podemos escrever:

(3) $\quad \mathrm{Ls}=L(\mathrm{r}, \mathrm{P})$

sendo, em princípio, $\mathrm{L}_{\mathrm{r}}>\mathrm{O}$ e $\mathrm{L}_{\mathrm{p}}>\mathrm{O}$ (voltaremos a esse ponto adiante).

A demanda de crédito (Ld) é função crescente do retorno líquido esperado pela firma - aqui denotado por $\mathrm{E}\left(\mathrm{RL}_{\mathrm{i}}\right)$. Este, por sua vez, é definido pelo retorno bruto esperado, $\mathrm{E}\left(\mathrm{RB}_{\mathrm{i}}\right)$, e pelas condições de pagamento do empréstimo nos casos de sucesso e fracasso do empreendimento, acima descritas. Por simplificação, admite-se também $\mathrm{E}\left(\mathrm{RB}_{\mathrm{i}}\right)=\mathrm{E}(\mathrm{RB})$, igual para todas as firmas ${ }^{8}$ :

$$
\mathrm{E}(\mathrm{RB})=\mathrm{P}_{\mathrm{i}} \mathrm{S}_{\mathrm{i}}+\left(1-\mathrm{P}_{\mathrm{i}}\right) \mathrm{F}
$$

Em caso de sucesso, o retorno líquido esperado $\left(\mathrm{RLS}_{\mathrm{i}}\right)$ define-se por:

$$
\operatorname{RLS}_{\mathrm{i}}=\mathrm{P}_{\mathrm{i}}\left[\mathrm{S}_{\mathrm{i}}-(1+\mathrm{r}) \cdot \mathrm{B}\right] \text {, onde } \mathrm{S}_{\mathrm{i}}>(1+\mathrm{r}) \cdot \mathrm{B}
$$

e, em caso de fracasso (retorno líquido $=$ RLFJ

$$
\operatorname{RLF}_{\mathrm{i}}=(1-\mathrm{P},)(\mathrm{F}-\mathrm{F})=0
$$

De (5) e ( 6), o valor esperado do retorno líquido da firma é:

$$
\mathrm{E}\left(\mathrm{RL}_{\mathrm{i}}\right)=\mathrm{P}_{\mathrm{i}}\left[\mathrm{S}_{\mathrm{i}}-(1+\mathrm{r}) \cdot \mathrm{B}\right]
$$

De (7), lembrando que B é fixo, a demanda de crédito da firma, Ld, pode ser escrita como:

$$
\mathrm{Ld}=\delta\left(\mathrm{P}_{\mathrm{i}}, \mathrm{S}_{\mathrm{i}}, \mathrm{r}\right) \text {, onde } \delta_{\mathrm{Pi}} ;>0 ; \delta_{\mathrm{si}} ;>0 ; \delta_{\mathrm{r}}<0
$$

Até aqui, o enfoque novo-keynesiano não se distingue substancialmente das abordagens convencionais do mercado de crédito, que conduzem ao equilíbrio walrasiano através do ajuste da taxa de juros: uma vez estimada a função densidade $\mathrm{g}(\mathrm{P}$,$) , que define a probabilidade-limite \mathrm{P}$, os bancos ofertarão maior volume de crédito quanto maior for a taxa de juros $\mathrm{r}$ aceita pelo mercado. Como $\delta_{\mathrm{r}},<0$ na

\footnotetext{
${ }^{8} \mathrm{O}$ objetivo dessa hipótese simplificadora é, segundo os autores, apenas ressaltar o ponto central da análise, que é a dificuldade de os bancos distinguirem entre os riscos (os Pi) de diversos projetos, ainda que seus retornos esperados sejam iguais. Contudo, como se discutirá adiante (seção 2.1), essa hipótese acaba sendo crucial à conclusão do MRC sobre os efeitos do aumento dos juros dos empréstimos pelos bancos.
} 
função Ld, o limite à oferta de crédito é dado apenas pela elasticidade-juros da função-demanda, de modo que o mercado se equilibre com Ls = Ld.

A novidade do MRC consiste, essencialmente, na rejeição ao ceteris paribus que, nessa análise, permite manter a distribuição de probabilidades $\mathrm{g}\left(\mathrm{P}_{\mathrm{i}}\right)$ inalterada à medida que $\mathrm{r}$ varia. Mais especificamente, o argumento é de que o elenco de probabilidades (de sucesso dos projetos) com que o banco opera é negativamente afetado pelo aumento em $r$, de modo que, diante de um quadro de excesso de demanda ( $\mathrm{Ld}>\mathrm{Ls}$ ), o banco opte por racionar quantitativamente Ls, em vez de elevar a taxa de juros. Sendo assim, o mercado se equilibra com Ld $>$ Ls, à mesma taxa já estabelecida - digamos $\mathrm{r}_{0}-$, e não com $\mathrm{Ld}=\mathrm{Ls}$ e $\mathrm{r}_{1}>\mathrm{r}_{0}$. Tal conclusão é uma implicação direta da forma como o modelo especifica as funções de comportamento das firmas. De (7),

$$
\mathrm{d}\left[\mathrm{E}\left(\mathrm{RL}_{\mathrm{i}}\right)\right] / \mathrm{dr}=-\mathrm{P}_{\mathrm{i} \cdot \mathrm{B}}<0
$$

A expressão (9) justifica a condição $\delta_{\mathrm{T}},<0$, mostrando que o retorno líquido esperado pela firma cai com o aumento em $\mathrm{r}$. Além disso, revela que a magnitude dessa queda é proporcional ao tamanho do empréstimo (B) e à probabilidade de sucesso da firma $\left(\mathrm{P}_{\mathrm{i}}\right)$. Como, no modelo, B é indivisível e igual para todas as firmas, o que distingue o efeito do aumento em $\mathrm{r}$ sobre os diversos projetos candidatos ao financiamento bancário são suas respectivas probabilidades de sucesso: a conclusão é a de que os projetos de investimento mais afetados negativamente pelo aumento nos juros são justamente aqueles de maior probabilidade de sucesso. Assim, um. aumento na taxa de juros dos empréstimos ajustaria a oferta à demanda, mas o faria de maneira desfavorável para o banco, excluindo justamente os (potenciais) tomadores de crédito de menor risco - este constitui o efeito seleção adversa a que se referem Stiglitz \& Weiss (1989).

Além da seleção adversa, argumenta-se, no MRC, que o aumento nos juros tenha também um efeito incentivo adverso para o banco, atraindo os projetos de menor probabilidade de sucesso e, portanto, de maior risco. Isso se explica porque, de acordo com (7), diante do aumento em r, as firmas que se manteriam como candidatas aos empréstimos bancários seriam aquelas de maior retorno bruto esperado em caso de sucesso, isto é, de maior $\mathrm{S}_{\mathrm{i}}$. Mas, a partir de (4), demonstra-se que, para $\mathrm{E}(\mathrm{RB})$ dado, os projetos de maior $\mathrm{S}_{\mathrm{i}}$ são justamente os de menor $\mathrm{P}_{\mathrm{i}}$ (ver Apêndice A).

Em suma, ao contrário do que sustenta a teoria convencional dos fundos emprestáveis, o aumento de juros não reduz marginalmente o valor da demanda de crédito das firmas, porque esse valor é, normalmente, indivisível para cada projeto de investimento. $\mathrm{O}$ aumento dos juros, assim, seleciona projetos inteiros e o faz de forma adversa para o banco, excluindo os de menor risco e mantendo - ou mesmo atraindo - os mais arriscados. $\mathrm{Na}$ função $\mathrm{E}(\mathrm{Rb})$, isso significa que:

$$
\mathrm{P}=p(\mathrm{r}), p^{\prime}<\mathrm{O}
$$

A expressão (10) sintetiza a ideia de que aumentos em $r$ tendem a piorar a 
qualidade do ativo do banco. Esta é a principal razão para que o aumento na taxa de juros não seja um instrumento eficiente de seleção de clientela pelo banco e é também o que justifica a possibilidade de equilíbrio com racionamento da demanda: se o aumento nos juros não é capaz de compensar o aumento no risco que incorre o banco ao elevar seu volume de empréstimos, o controle de risco é feito, diretamente, pela limitação do seu grau de exposure no mercado 9 . formalmente, o argumento é demonstrado a partir da derivada $\mathrm{d}[\mathrm{E}(\mathrm{Rb})] / \mathrm{dr}$, dada por:

$\mathrm{p}$

$$
d[E(R b)] / d r=B \cdot \int P_{i} g\left(P_{i}\right) d P_{i}+p^{\prime} \cdot[(1+r) \cdot B \cdot P g(P)+F \cdot(1-P) \cdot g(P)]
$$

0

Note-se que, se $\mathrm{P}$ fosse independente de $\mathrm{r}$, teríamos $p^{\prime}=0$ e o efeito do aumento em $\mathrm{r}$ sobre $\mathrm{E}(\mathrm{Rb})$ se reduziria ao primeiro termo do lado direito de (11), que é positivo. Com $p^{\prime}<0$, porém, esse efeito positivo é gradativamente reduzido, à medida que $\mathrm{r}$ se eleva, de modo que exista uma taxa $\mathrm{r}$ * ótima (máxima), que maximiza $\mathrm{E}(\mathrm{Rb}) \mathrm{e}$, assim, determina Ls (também máximo) para cada estado das expectativas de retorno - leia-se: para cada distribuição da probabilidade $P_{i}$. Nessas condições, o racionamento (da demanda) surge sempre que $\operatorname{Ls}\left(\mathrm{r}^{*}\right)<\operatorname{Ld}\left(\mathrm{r}^{*}\right)-$ como na Figura $1-\mathrm{e}$ essa situação, uma vez configurada, é de equilíbrio porque não existe uma variável comum que ajuste, simultaneamente, as quantidades Ld e Ls.

Figura 1

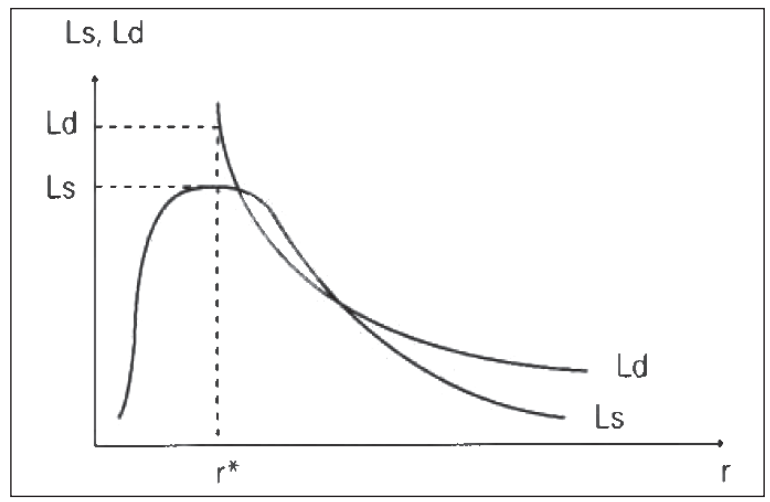

\footnotetext{
${ }^{9}$ Embora a ênfase aqui e no texto de Stiglitz \& Weiss seja na tendência à rigidez da $\mathrm{r}$ à alta, os autores também argumentam a favor da tendência à rigidez dar à baixa, com base (implicitamente) na hipótese de uma "curva de demanda quebrada" para os clientes de melhor risco: "If a bank tries to attract the customers of its competitors by offering a lower interest rate, it will find that its offer is countered by an equally low interest rate when the customer being competed for is a 'good' credit risk and will not be matched if the borrower is not a profitable customer of the bank. Consequently, banks (...) will only succeed in attracting the least profitable of those customers (... ). In equilibrium each bank may have an excess supply of loanable funds, but no bank will lower its interest rate" ( pp. 272-273).
} 


\subsection{O MRC e o mecanismo de transmissão da política monetária}

Algumas implicações do MRC para a questão do papel e do modo de operação da política monetária na visão novo-keynesiana já foram comentadas na seção 1.1. $\mathrm{O}$ argumento, em resumo, pode ser colocado nos seguintes termos: o equilíbrio com racionamento da demanda, como resultado da racionalidade dos bancos, explica a atuação do sistema bancário na criação endógena de restrições ao pleno emprego; essa atuação, por sua vez, justifica a conveniência da política monetária anticíclica. Quanto ao modo de operação dessa política, porém, Stiglitz \& Weiss (1989) são menos explícitos, sugerindo apenas que seu mecanismo de transmissão se dá diretamente pela oferta de crédito, sem qualquer intermediação da taxa de juros:

“(...) in a rationing equilibrium, to the extent that monetary policy succeeds in shifting the supply of funds, it will affect the level of investment not through the interest-rate mechanism but rather through the availability of credit." (p. 272)

Uma versão do mecanismo de transmissão implícito no MRC (ou compatível com ele) é apresentada em Blanchard \& Fisher (1994, pp. 482-483 e 486-488). Nessa versão, sumariamente reproduzida na Figura 2, explica-se a relação entre a oferta de crédito e o passivo bancário. Desse ponto de vista, Ls é uma função crescente da disponibilidade de fundos do banco (DF), sendo:

$$
\mathrm{DF}=\mathrm{D}\left(\mathrm{r}_{\mathrm{d}}\right)+\mathrm{RE} \text {, onde: }
$$

$\mathrm{D}\left(\mathrm{r}_{\mathrm{d}}\right)=$ depósitos captados junto ao público, à taxa $\mathrm{r}_{\mathrm{d}}$, sendo $\mathrm{D}^{\prime}>0 ; \mathrm{r}_{\mathrm{d}}=$ custo da captação de depósitos junto ao público, que, por simplificação, Blanchard \& Fisher assumem ter uma relação direta com a taxa de retorno esperado do banco, dada por $\mathrm{r}_{\mathrm{b}}=\mathrm{E}(\mathrm{Rb}) / \mathrm{B} ; \mathrm{RE}=$ reservas captadas junto a outros bancos, inclusive o banco central ${ }^{10}$.

Figura 2

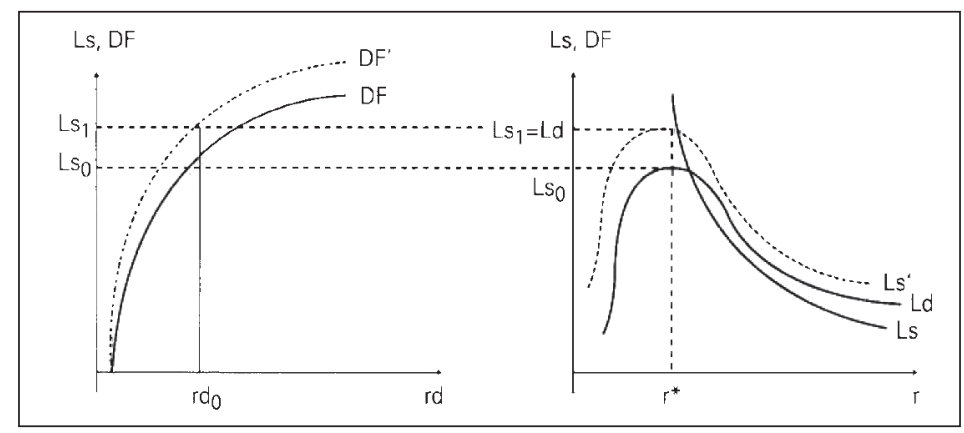

\footnotetext{
${ }^{10}$ Os autores se referem, explicitamente, às reservas tomadas de empréstimo junto ao Banco Central, de modo que RE represente as reservas criadas através da "janela de redesconto". Para tornar o modelo mais genérico, porém, podemos incluir também em RE as reservas criadas pelo Banco Central em suas operações de open market, bem como as obtidas no mercado interbancário.
} 
Como mostra a Figura 2, a política monetária atua deslocando a curva Ls (do lado direito da figura) para cima, fazendo-o através do deslocamento, na mesma direção, da curva DF (do lado esquerdo). A mecânica da operação seria, basicamente, a seguinte: (i) o banco central expande as reservas bancárias, por meio de qualquer de seus instrumentos; (ii) a expansão de RE amplia a disponibilidade de fundos emprestáveis dos bancos, para uma mesma taxa de captação $r_{d}$, deslocando a curva DF para a posição superior DF'; (iii) a expansão de DF permite um aumento da oferta de crédito pelos bancos, à mesma taxa de juros "ótima" $r$ " • (definida como exposto na seção anterior).

Combinando essa análise com a desenvolvida na seção 1.2, podemos escrever:

$$
\mathrm{Ls}=\Phi\left(\mathrm{r}^{*}, \mathrm{r}_{\mathrm{d}}, \mathrm{RE}\right), \Phi_{\mathrm{r}^{\mathrm{e}}}>0 ; \Phi_{\mathrm{rd}},>0 ; \Phi_{\mathrm{RF}}>0
$$

A taxa $r^{*}$. sintetiza a influência das variáveis $r$ e $P$ explicitadas na função (3), que, por sua vez, refletem a racionalidade dos bancos na definição da composição de seu ativo; rd e RE representam a influência das condições do passivo bancário e, por conseguinte, da política monetária, na determinação da oferta de crédito.

\section{ALCANCE E LIMITAÇÕES DO MRC}

\subsection{Definição do problema}

As mais relevantes conclusões do MRC podem ser sintetizadas nas seguintes proposições: (i) além do efeito direto e positivo sobre a receita do banco, a taxa de juros dos empréstimos pode ter efeitos adversos sobre a qualidade do seu ativo (efeitos seleção e incentivo ); ( ii ) dado ( i ), a taxa de juros não é um mecanismo de market clearing, mas, fundamentalmente, um instrumento de administração de risco pelo banco - e, nessa função, a taxa é rígida em relação à demanda de crédito; ( ii i) de ( i ) e (ii), o equilíbrio com racionamento da demanda torna-se um resultado plausível nesse mercado, pela ausência de um mecanismo endógeno que ajuste oferta e demanda; (iv) reconhecendo-se que a insuficiência de crédito atua como um limite aos investimentos, conclui-se que a condição ( iii ) é uma das causas (entre outras) da possibilidade de equilíbrio do produto com desemprego (não só da mão-de-obra, mas dos fatores de produção em geral); ( v) a política monetária anticíclica é recomendável e eficaz nesses casos, sendo seu mecanismo de transmissão independente da flexibilidade da taxa de juros.

As três primeiras proposições sintetizam a interpretação novo-keynesiana a respeito da racionalidade dos bancos e, indiretamente, das firmas tomadoras de crédito, num ambiente marcado pela assimetria de informação. Embora o argumento se desenvolva em termos microeconômicos (para bancos e firmas individuais), tal interpretação sustenta conclusões sobre o papel dos bancos na determinação do nível de investimento agregado (proposição iv) e sobre o papel e o modo de operação da política monetária (proposição v), que são questões macroeconômicas por excelência. A análise novo-keynesiana sobre essas questões apóia-se, por- 
tanto, em um modelo de "firma (bancária) representativa", no qual supõe-se ser possível inferir o comportamento agregado (do mercado de crédito) a partir do comportamento individual (de um banco "típico"). Sendo assim, devemos admitir que, na visão novokeynesiana, o equilíbrio com racionamento descrito por Stiglitz $\&$ Weiss é um fenômeno macroeconômico e é, precisamente, por essa razão que se torna um argumento relevante no debate sobre política monetária.

O método da "firma representativa" é um traço comum aos modelos macroeconômicos de cunho ortodoxo, que recusam a análise de "agregados", como variáveis distintas das partes que os compõem, em favor da busca de fundamentos microeconômicos. Como mostrou Keynes (1985), a utilidade desse método para a análise macroeconômica é discutível, restringindo-se aos casos em que a possibilidade de "falácia de composição" possa ser afastada — ou seja, em que a variável agregada não se caracterize por uma dinâmica de comportamento qualitativamente distinta da identificada para a variável microeconômica. A opção de Keynes pelo método agregado - na verdade, pela sua criação — tem origem na avaliação, com base em argumentos lógicos, de que esses casos eram, no mínimo, improváveis para as variáveis macroeconômicas relevantes (investimento, poupança, emprego, consumo, produto etc.). ${ }^{11}$

Com base no argumento da "falácia de composição", a seção 2.2. a seguir discute e questiona a validade do MRC como instrumento teórico adequado à análise do papel dos bancos e da política monetária na dinâmica da economia. Argumentase que, embora o equilíbrio com racionamento da demanda seja aceitável como resultado da racionalidade de um banco individual, quando transposto para o plano macroeconômico, ele implica hipóteses pouco plausíveis a respeito da atuação do sistema bancário, especialmente nas fases expansivas dos ciclos econômicos. Em consequência dessa análise, questiona-se também a interpretação novo-keynesiana a respeito do papel e mecanismo de transmissão da política monetária - objeto da seção 3.

\subsection{O racionamento como fenômeno macroeconômico}

Antes de iniciar esta discussão, convém lembrar um alerta de Stiglitz \& Weiss (1989), que esclarece o ponto central do argumento dos autores e da crítica aqui proposta:

\footnotetext{
$11 \mathrm{O}$ mais conhecido exemplo de falácia de composição apontado por Keynes é o do "paradoxo da parcimônia": um indivíduo que pretende elevar sua poupança, pode fazê-lo reduzindo seu consumo (para um dado nível de renda ); porém, se uma sociedade inteira decidir reduzir seu consumo (C), visando aumentar seu nível de poupança agregada $(\mathrm{S})$ - supostamente para financiar um aumento do investimento agregado (1) —, o resultado não será o aumento em $S$, mas a redução, uma vez que a queda do consumo implica a redução da renda agregada, $1(\mathrm{Y})$, da qual depende a poupança. Ou seja, no agregado, $\mathrm{S}=\mathrm{S}(\mathrm{Y})$ e $\mathrm{Y}=\mathrm{Y}(\mathrm{C}, 1)$ - economia fechada e sem governo, por simplificação —, sendo todas as derivadas positivas; portanto, se C se reduz, o mesmo ocorre com Y e S. Outro exemplo típico é o da redução de salários como meio de estimular o emprego: de fato, se uma em presa consegue obter trabalhadores por um salário menor, seu lucro por unidade de produto e seu nível de emprego "ótimo" poderão ser elevados; contudo, se todas as empresas o fizerem, o resultado será uma queda no consumo e, portanto, nas vendas, nos lucros e no nível de emprego.
} 
"It is not our argument that credit rationing will always characterize capital markets but rather that it may occur under not implausible assumptions concerning borrower and lender behavior.” (p. 249, grifos meus)

A análise a seguir visa mostrar justamente o contrário: que as hipóteses necessárias à sustentação do resultado do MRC para o mercado - e não somente para um banco ou projeto individual - não são plausiveis. No que se segue, procura-se identificar as hipóteses implícitas ou necessárias à validade desse resultado.

Para um banco individual, o equilíbrio com racionamento da demanda ocorre quando $\operatorname{Ls}\left(\mathrm{r}^{*}\right)<\mathrm{Ld}\left(\mathrm{r}^{\text {** })}\right.$. Transpondo essa relação para o mercado de crédito, obtémse uma situação típica de excesso de demanda: a demanda agregada de empréstimos, à taxa $r^{*}$ supera a oferta agregada, sendo essa última formada pelo somatório das diversas ofertas individuais, determinadas como descrito anteriormente. As condições implícitas na configuração de um quadro de equilíbrio com demanda racionada são, basicamente, duas: (i) que existam firmas com planos de investimento e demanda de crédito (ou seja, com investimentos planejados em $\mathrm{K}>\mathrm{W}$ ); (ii) que esses planos estejam sendo restringidos pelo crédito por livre e racional escolha dos bancos.

O racionamento da demanda de crédito, previsto no MRC, representa, assim, uma situação na qual o investimento é obstado apenas pela restrição orçamentária das firmas, mas não por baixos retornos esperados. Numa interpretação keynesiana fiel à "Teoria Geral”, podemos afirmar que se tratar, pelo menos, do início de uma fase ascendente do ciclo econômico, já que o limite ao investimento não é dado pela (baixa) eficiência marginal do capital. No cenário em que se inscreve o MRC, portanto, o sistema bancário não atua como "o" causador do equilíbrio com desemprego, mas, fundamentalmente, como limite à uma taxa de crescimento que, de outro modo - isto é, se a racionalidade dos bancos se manifestasse de outra forma - seria maior. Para tornar mais clara a dinâmica bancos-firmas suposta no MRC, é interessante contrastá-la com a conhecida e pioneira abordagem wickselliana sobre essa matéria. No processo cumulativo descrito por Wicksell (1985), admitese também que os bancos definiram suas taxas de juros de mercado por critérios de maximização de lucros. Contudo, uma vez definidas, admite-se que os bancos tenham uma postura passiva diante da demanda por empréstimos, sancionando tanto o excesso quanto a insuficiência de demanda — pela expansão do crédito no primeiro caso e pela contração no segundo. Nessa visão, portanto, bancos atuam como agentes propagadores das fases ascendente e descendente dos ciclos econômicos — daí a ideia do processo cumulativo.

No MRC, ao contrário, admite-se que, diante de um quadro de excesso de demanda, os bancos reagem racionando o crédito, em vez de expandi-lo mediante aumento dos juros. Dessa forma, impedem a conversão do excesso de demanda no mercado de crédito em demanda adicional no mercado de bens (de capital e, indi- 
retamente, de consumo); em outros termos, impedem a materialização da "conexão wickselliana" 12

Aceita a análise novo-keynesiana, portanto, concluiremos que os bancos atuam como "estabilizadores automáticos" (endógenos) do ciclo expansivo. O fato de essa tese já ter sido fartamente negada pela evidência empírica, bem como por trabalhos teóricos de filiações diversas ${ }^{13}$, é uma forte razão para a rejeição da hipótese de racionamento como expressão do equilíbrio do mercado de crédito - embora ela seja aceitável para bancos individuais. Alguns argumentos desses trabalhos teóricos são comentados a seguir.

Antes de mais nada, convém observar que, para justificar a atuação pró-cíclica e, potencialmente, instabilizadora do sistema bancário na economia, não é necessário aderir ao extremo wickselliano, em que se supõe bancos totalmente passivos diante da demanda. Ao contrário, a atuação do sistema bancário é mais facilmente compreensível se considerarmos que bancos são firmas que, como quaisquer outras, perseguem o lucro máximo possível, dentro das circunstâncias vigentes. Como bancos são tipicamente firmas que operam " alavancadas" ("agentes especulativos", no sentido de Minsky), que financiam uma parte significativa de seu ativo com dívidas, a maximização do lucro requer a administração sistemática do ativo e do passivo, envolvendo a administração dos volumes, custos e riscos envolvidos em cada um desses itens. ${ }^{14}$

Considerando os dois aspectos (ativo e passivo bancários) conjuntamente, constata-se que, embora o equilíbrio com racionamento seja compreensível (racional) diante de um excesso de demanda localizado (para um banco específico), não o é quando esse excesso atinge o mercado de crédito em seu conjunto. Nesse caso, diversos fatores atuam como pressão, ou mesmo incentivo, para que os bancos busquem atender à demanda adicional e para que, de um modo geral, o façam mediante aumento nos juros dos empréstimos.

Em primeiro lugar, como a demanda de crédito é, em sua maior parte, uma demanda derivada das decisões de produção e investimento das firmas ${ }^{15}$, uma si-

\footnotetext{
${ }^{12}$ De forma sintética, a "conexão wickselliana” estabelece que, a um excesso de demanda no mercado de bens corresponde, sempre, um excesso de oferta no mercado monetário, do qual faz parte o crédito bancário (além da moeda legal emitida pela autoridade monetária). Ver, a respeito, Simonsen (1983), pp. 26-30, e Leijonhufvud (1981b).

${ }^{13}$ Ver, por exemplo, o próprio Wicsell (1985), de filiação neoclássica, Keynes (1979), cap. 25, Minsk y (1982), cap. 2, e (1986), cap. 10.

${ }^{14}$ Para um survey comentado das teorias de firma bancária ver Baltensperger (1980), Santomero (1984) e Machado (1995), cap. 1; sobre a teoria keynesiana da firma bancária, ver Machado (1995), cap. 2, e Bezerra (1994).

15 Além dessas decisões, determinam ainda a demanda de crédito as decisões de consumo de bens duráveis e as necessidades de refinanciamento de dívidas. A demanda associada ao consumo de bens duráveis, porém, é, indiretamente, derivada das decisões de produzir e investir das firmas — afinal, são essas decisões que criam a renda que sustenta o consumo à vista e a capacidade de endividamento dos consumidores. Quanto às necessidades de rolagem de dívidas, embora sejam, normalmente, de volume e papel importantes na dinâmica da economia, só explicam o excesso de demanda de crédito em casos
} 
tuação de excesso de demanda no mercado de crédito caracteriza um período de expectativas de retorno otimistas por parte das firmas. Admitir que os bancos não têm interesse em atender a essa demanda (porque já definiram suas $\mathrm{r}^{*} \mathrm{e}$ Ls "ótimas") implica supor que as expectativas e o estado de confiança das "firmas bancárias" sejam formados em um ambiente imune aos fatores que deram origem às expectativas, mais otimistas, das firmas não-bancárias. Como tal hipótese não parece defensável, resta admitir que, diante de um quadro de excesso de demanda generalizado, os bancos reajam tentando aproveitar as novas oportunidades do mercado - assim como fazem as demais firmas —, o que, provavelmente, resultará em ampliação da oferta de crédito. Em segundo lugar, vale lembrar que, num ambiente dessa natureza, a recusa de alguns bancos em atender à demanda adicional das firmas acarretará perda de mercado para seus concorrentes, o que, num "mercado de clientela" - orientado por relações de longo prazo —, como é o mercado de crédito, deve ser evitado.

Uma questão que se coloca nesse ponto é se os bancos têm condições de distinguir entre um excesso de demanda localizado e um generalizado. Os efeitos do excesso generalizado sobre o passivo bancário sugerem que sim. Admitindo-se que as firmas mantenham, além de depósitos à vista, aplicações financeiras (depósitos a prazo) no sistema bancário, a demanda de crédito, não satisfeita, as induzirá a converter depósitos a prazo em depósitos a vista, o que eleva os requisitos de reservas dos bancos. Se esse movimento for generalizado, o custo das reservas no mercado interbancário se elevará, aumentando, assim, um dos itens do custo de captação dos bancos. Uma reação natural, nesses casos, é que os bancos reduzam a taxa que pagam sobre depósitos do público (a taxa rd das funções 12 e 13), como forma de compensar o aumento de custo no interbancário. Isso, porém, resultará em novas rodadas de conversão de aplicações em depósitos à vista, elevando ainda mais a necessidade de reservas.

Assim, ao contrário do que se pode esperar de um excesso de demanda de crédito localizado, que não afeta as condições de captação do sistema bancário, no caso de um excesso generalizado a composição e custo do passivo dos bancos são desfavoravelmente atingidos. Esse efeito torna perceptível que se trata de uma mudança nas condições gerais do merca do - e não na demanda específica do banco - e explica porque, diante do excesso de demanda no mercado de crédito, os bancos tendem não só a expandir a oferta, mas também a aumentar os juros dos empréstimos: caso contrário, veriam seus spreads reduzidos, comprometendo seu retorno líquido.

Finalmente, no escopo do MRC, a perspectiva de aumento dos juros requer um comentário sobre os efeitos seleção adversa e incentivo que o modelo associa a tal medida. No MRC, como vimos, esses efeitos decorriam de duas condições, respectivamente: da forma como se descreve a função retorno líquido esperado das

excepcionais, de grave recessão e crise financeira. Nesses casos, que serão tratados adiante, o equilíbrio com racionamento é, de fato, mais plausível, mas não exatamente nos moldes descritos pelo MRC. 
firmas - E(RL,), expressão (7) - e da hipótese simplificadora de que todas as firmas tenha $m$ o mesmo retorno bruto esperado $-E(R B)$, expressão (4). Com base nessas funções e em argumentos lógicos, demonstra-se que, se há um excesso de demanda generalizado no mercado de crédito, gerado por expectativas mais otimistas quanto ao retorno das firmas, o aumento dos juros não necessariamente terá aqueles efeitos.

O efeito seleção adversa foi constatado a partir da relação $\mathrm{d}[\mathrm{E}(\mathrm{RL})] / \mathrm{dr}=-\mathrm{P}_{\mathrm{i}} \cdot \mathrm{B}$ (expressão 9 ), mostrando que o aumento do juro pelo banco resultava na exclusão de seu portfólio potencial, dos projetos de maior probabilidade de sucesso. É razoável supor que isso, de fato, ocorra quando o aumento em $r$ é uma decisão de um banco individual: nesse caso, as firmas excluídas podem tentar obter crédito em outros bancos cujas taxas de juros não tenham sido majoradas. No entanto, se o aumento for generalizado - e tende a sê-lo, pelas razões expostas no parágrafo anterior -, as firmas terão duas alternativas: manter os planos de investimento, aceitando o juro maior, ou abrir mão do investimento. É pouco provável que optem pela segunda delas num ambiente em que as expectativas de retorno bruto são mais favoráveis que antes. Ou seja, nos termos da expressão (7), se os retornos esperados $S_{i}$ (de sucesso) estão se elevando com os juros, o retorno líquido esperado $E\left(R L_{i}\right)$ pode manter-se inalterado, alimentando, assim, a demanda de crédito das firmas, inclusive as de menor risco (maior P;). Isso evitaria o efeito seleção adversa.

A partir de (4), demonstra-se facilmente que, se os retornos brutos esperados $\mathrm{E}(\mathrm{RB})$ crescem enquanto se elevam os juros, o efeito incentivo (adverso) não necessariamente se verifica - ou seja, maiores $\mathrm{S}_{\mathrm{i}}$ e $\mathrm{E}(\mathrm{RB})$ não implicam menores $\mathrm{P}_{\mathrm{i}}$, de modo que, aos olhos dos bancos, o aumento dos juros não necessariamente atraia as firmas de maior risco para seu portfólio (ver demonstração no Apêndice B).

Essas considerações não pretendem provar que a expansão do crédito, numa situação de excesso de demanda, não deteriora a qualidade do ativo bancário, como propõe o MRC. Ao contrário, como demonstra Minsky (op. cit.), a expansão do crédito, característica das fases de maior prosperidade e otimismo, tende a elevar o grau de fragilidade financeira dos bancos e das firmas em geral. ${ }^{16} \mathrm{O}$ que se rejeita é que, num ambiente de expectativas mais favoráveis, os bancos sejam mais capazes de perceber o movimento de fragilização do que as demais firmas. A aceitação de tal hipótese, como vimos, implicaria admitir que as expectativas e o estado de confiança das "firmas bancárias" sejam imunes aos fatores que orientam as decisões das firmas não-bancárias. Não sendo esse o caso, resta admitir que bancos são agentes naturalmente mais cautelosos - menos propensos a riscos - que as firmas nãobancárias. Como nenhuma das duas hipóteses é razoável, conclui-se que

\footnotetext{
${ }^{16}$ Das firmas, porque o novo e maior endividamento apoia-se em expectativas de maior retorno que podem ser confirmadas ou não, além de que tende a se dar sob custos maiores aceitos exatamente em função das melhores expectativas de retorno: dos bancos, porque, além do risco de inadimplência das firmas mais otimistas, o rápido aumento dos depósitos à vista, que acompanha a expansão do crédito, leva ao encurtamento do prazo médio de seus passivos, ao passo que os novos empréstimos alongam o prazo médio do ativo.
} 
a fragilização não é, normalmente, evitada pelo comportamento racional dos bancos e que estes, ao contrário do que sugere o MRC, não atuam como "estabilizadores automáticos" nas fases expansivas do ciclo econômico.

$\mathrm{Na}$ fase recessiva do ciclo, o equilíbrio com racionamento da demanda é, em princípio, plausível, mas não exatamente pelas razões alegadas no MRC. Nessa fase, o eventual excesso de Ld sobre Ls não pode ser atribuído a um volume elevado de planos de investimento, porque ela se caracteriza, justamente, por fracas expectativas de retorno. A demanda insatisfeita, nesse caso, é predominantemente associada às necessidades de refinanciamento de dívidas pelas firmas cujas expectativas de retorno não se confirmaram ou que, propositadamente, assumiram posturas devedoras "especulativas" (no sentido de Minsky). Nesse contexto, as condições de operação do mercado de crédito são bem distintas das descritas no MRC: (i) a demanda de crédito torna-se, em grande parte, inelástica; (ii) o retorno líquido esperado pelas firmas - E(RLi) - torna-se, portanto, irrelevante para a determinação da sua demanda de crédito; (iii) o espaço de que dispõem os bancos para elevar os juros é ampliado, porque as firmas de menor risco (maior $P$ ) não serão excluídas de seu portfólio por essa medida; (iv) o universo de probabilidades de sucesso com que o banco opera é desfavoravelmente afetado, reduzindo-se a probabilidade máxima $P$.

Em suma, na fase recessiva do ciclo econômico, o racionamento não ocorre em consequência da rigidez dos juros à alta — como sustenta o MRC —, mas da redução da probabilidade (máxima) $\mathrm{P}$, que afeta negativamente o retorno esperado pelo banco - o termo $\mathrm{E}(\mathrm{Rb})$ da expressão (2). Ou seja, sendo $\mathrm{Ls}=\mathrm{L}(\mathrm{r}, \mathrm{P})$ e $L_{\mathrm{p}}>0$, a queda de $\mathrm{P}$ explica, diretamente, a retração de Ls, que, em um contexto de demanda de crédito inelástica, pode facilmente levar a um quadro de racionamento. $\mathrm{E}$, como o aumento dos juros é mais provável que a rigidez em ambientes recessivos (pelas razões já comentadas), o grau de racionamento pode ser reforçado por essa atitude dos bancos. Assim como na análise da fase expansiva, conclui-se que o comportamento racional dos bancos e as condições características de cada fase do ciclo atuam no sentido de tornar o sistema bancário um agente propagador - e não estabilizador - dos ciclos econômicos.

\section{CRÍTICA AO ENFOQUE NOVO-KEYNESIANO DA POLÍTICA MONETÁRIA}

\subsection{Sobre o papel da política monetária}

A análise precedente tem implicações para a discussão a respeito do papel da política monetária. Se, diante de um quadro de excesso de demanda, a expansão do crédito não é impedida pela tendência à deterioração do ativo bancário (em termos de risco), o racionamento descrito no MRC não é um fenômeno macroeconômico, devendo ser visto como um evento localizado em bancos e/ou projetos de investimento específicos. Como tal, não justifica qualquer posição a respeito de 
intervenções "horizontais" no mercado de crédito, como é o caso da política monetária, muito menos no sentido expansivo. Ao contrário, a política monetária ativa recomendável nesse contexto é no sentido de conter a tendência do sistema bancário a seguir o animal spirits das firmas não-bancárias, a partir do momento em que este se mostre excessivamente otimista. Em suma, o papel da política monetária, nesse caso, é, essencialmente, o de zelar pela solidez do sistema financeiro e, indiretamente, do próprio ciclo expansivo.

Quanto à fase recessiva do ciclo, como vimos, o equilíbrio do mercado de crédito com racionamento da demanda é um resultado plausível. Contudo, embora essa condição recomende a intervenção anticíclica da política econômica, ela não atua em auxílio ao mecanismo de transmissão da política monetária, ao contrário do que sustenta a abordagem novo-keynesiana, apoiada no MRC. Esta questão é discutida na seção seguinte.

\subsection{Sobre o mecanismo de transmissão da política monetária}

Sobre o mecanismo de transmissão da política monetária, em um mercado de crédito caracterizado pelo equilíbrio com racionamento, Stiglitz \& Weiss (1989) afirmam:

"Although this is a 'monetarist' result, it should be apparent that the mechanism is different from that usually put forth in the monetarist literature." (p. 272, grifos meus)

A diferença a que se referem os autores, como vimos na seção 1.3, reside no fato de que a transmissão se dá diretamente pela oferta de crédito, sem passar pela intermediação da taxa de juros. Na mesma linha de argumentação, Mankiw \& Romer (1989) reivindicam um posto distintivo para o MRC, não só em relação à visão monetarista, mas também em relação à keynesiana convencional (identificada com o modelo IS-LM ):

"In the traditional textbook model, restrictive monetary policy is transmitted to aggregate demand by reducing the money stock and thus raising interest rates to clear the market for money. (... ) Research on credit-market imperfections has challenged two separate features of this account. The first concerns the special role of money. By reducing the quantity of bank reserves, monetary policy may have a direct impact on banks' ability to lend. (...) Thus, the transmission mechanism may operate in part through a direct impact on bank loans; in the extreme, the impact on money [market/ may be irrelevant. (...) The second challenge (...) focuses on whether the reduction in lending takes place through increases in interest rates or through rationing. Stiglitz and Weiss [e outros] demonstrate that rationing may be central to the transmission mechanism.” (pp. 12-13, grifos meus) 
Em suma, segundo esses autores, o MRC permitiria justificar a conveniência e a eficácia da política monetária anticíclica de uma forma inovadora e sem passar pelo incômodo (e, nessa visão, irrelevante) debate a respeito da elasticidade-juro da demanda por moeda, há décadas polarizado por keynesianos e monetaristas. A análise crítica a seguir contesta o caráter supostamente inovador da abordagem novo keynesiana da política monetária, identificando o mecanismo de transmissão por ela descrito com o enfoque monetarista. Além disso, contesta-se a adequação desse enfoque para a análise do papel e o modo de operação da política monetária em um ambiente caracterizado - como os próprios novos-keynesianos enfatizam - pela assimetria de informação e pela presença de agentes racionais que, além de vi sarem lucro, administram os riscos inerentes a esse ambiente.

O debate sobre a importância da elasticidade-juro da demanda por moeda (E,) na dinâmica macroeconômica foi inaugurado por J. Hicks, em 1937, em seu famoso artigo Mr. Keynes and the Classics (Hicks, 1983). Nele, o autor identificou como principal distinção entre a teoria monetária de Keynes e a teoria (neo)clássica, que Keynes criticava, as diferentes hipóteses, implícitas ou explícitas nessas interpretações, sobre a relação entre demanda por moeda $\left(\mathrm{M}^{\mathrm{d}}\right)$ e taxa (primária) de juros $\left(\mathrm{r}_{\mathrm{p}}\right) \cdot{ }^{17}$

Enquanto os clássicos entendiam $\mathrm{M}^{\mathrm{d}}$ como uma função estável da renda nominal, Keynes reconhecia e enfatizava a influência (negativa) de $r_{p}$ sobre $\mathrm{M}^{\mathrm{d}}$. $\mathrm{O}$ argumento de Keynes a esse respeito é bastante conhecido: admitindo que, ao proporcionar a segurança da liquidez, a moeda cumpria também a função de reserva de valor (além de meio de troca), a decisão racional do público quanto à retenção "ótima" de moeda deveria levar em conta sua avaliação sobre a taxa de retorno dos ativos alternativos capazes de cumprir a mesma função, refletida na taxa de juros. Assim, segundo Keynes, era necessário agregar à demanda transacional por moeda uma nova componente, de caráter especulativo, inversamente relacionada aos movimentos efetivos e esperados da taxa de juros.

Considerando ambas as visões lógica e teoricamente válidas, Hicks sustentou que as teorias monetárias keynesiana e clássica eram, na verdade, complementares, e não antagônicas. Tratava-se, então, apenas de identificar as condições (ou casos) em que cada uma seria válida. A partir dessa análise, a abordagem de Keynes, traduzida nos termos do modelo IS-LM proposto pelo próprio Hicks, passou a ser identificada com a crença nas hipóteses de elasticidade-renda $\left(\mathrm{E}_{\mathrm{y}}\right)$ baixa e $\mathrm{E}_{\mathrm{r}}$ significativa, enquanto o modelo clássico se caracterizava por admitir $E_{y}$ alta e $E_{r}$ desprezível.

As elasticidades clássicas seriam características de economias a pleno emprego, em que a renda nominal e a taxa de juros estão elevadas, de modo que a demanda

\footnotetext{
${ }^{17} \mathrm{O}$ uso da notação $r_{p}$, em lugar de $r$, visa frisar que, no debate sobre a sensibilidade-juro da demanda por moeda, a taxa de juros relevante é a do mercado de títulos de alta liquidez, e não a taxa dos empréstimos bancários. Deve ficar claro, portanto, que essa discussão refere-se ao mercado monetário, e não ao mercado de crédito.
} 
transacional por moeda absorva, praticamente, toda a oferta disponível e a demanda especulativa torne-se aproximadamente nula. Analogamente, $\mathrm{E}_{\mathrm{y}}$ baixa e $\mathrm{E}_{\mathrm{r}}$ elevada (caso keynesiano) seriam características de economias em depressão — daí a famosa conclusão de Hicks de que "a Teoria Geral do Emprego é a Teoria Econômica da Depressão" (Hicks, op. cit., p. 153): em tais economias, a renda nominal e a taxa de juros estão baixas, de forma que a resposta da demanda transacional a variações na oferta de moeda é fraca e a demanda especulativa absorve a maior parte da moeda disponível. A partir dos anos 50, desenvolveu-se uma versão empírica deste debate, inaugurada por M. Friedman (1956 e 1959) ${ }^{18}$ que, no entanto, não logrou estabelecer a hegemonia de uma das duas posições, tampouco a perfeita conciliação entre as visões clássica e keynesiana sobre a matéria, de modo que a antiga controvérsia se mantém como questão teórica de relevo.

As implicações desse debate para a análise do mecanismo de transmissão da política monetária são claras: se a demanda por moeda reage à taxa primária de juros - que, a curto prazo, é a variável diretamente afetada pelas oscilações da oferta de moeda (quanto a isso não há controvérsia)-, o processo de transmissão da política monetária para o "lado real" da economia não ocorre de forma direta. Esse processo passa a depender da intensidade do efeito da mudança em $r$ sobre a demanda por moeda, ou seja, da magnitude de E, Diante de uma política expansiva, por exemplo, que reduz $\mathrm{r}_{\mathrm{p}}, \mathrm{E}_{\mathrm{r}}$, alta implicará a retenção de grande parte da moeda adicional no próprio mercado monetário, reduzindo, assim, seu "vazamento" para a demanda de bens e serviços e, portanto, o efeito "real" da expansão monetária. Alternativamente, E, desprezível, como admite a visão clássica, torna a política monetária altamente influente sobre a demanda agregada de bens e serviços - ainda que apenas em termos nominais, já que, nessa visão, prevalece a tese da tendência da economia ao pleno emprego.

Outra implicação das diferentes interpretações de E, para o entendimento do mecanismo de transmissão da política monetária diz respeito à atuação dos bancos nesse processo. Se, como propõe o modelo clássico, a demanda especulativa por moeda não é relevante a ponto de justificar a introdução $r_{p}$ na função $\mathrm{M}^{\mathrm{d}}$, as variações provocadas pela política monetária nas reservas bancárias serão direta e proporcionalmente transmitidas ao público. Essa interpretação sustenta o conhecido modelo de multiplicador bancário, que estabelece uma relação direta e supostamente estável entre a base monetária e a oferta de meios de pagamento, através do crédito bancário. No enfoque keynesiano, ao contrário, essa relação não é direta nem deve ser supostamente estável, já que depende também da reação da demanda por moeda dos bancos às mudanças em $r_{p}$.

Leituras extremadas das hipóteses keynesiana e clássica a respeito de E, deram origem, respectivamente, às interpretações hoje conhecidas como "fiscalista" e

\footnotetext{
${ }^{18}$ Ver também, a esse respeito, os conhecidos trabalhos de Goldfeld (1973) e Laidler (1977). Para um survey das abordagens empíricas da demanda por moeda, ver Triches (1992).
} 
"monetarista". ${ }^{19}$ Evitando os extremos, mas conservando a proposição de Keynes sobre a função da moeda como reserva de valor - e, portanto, sobre a existência de uma relação não desprezível entre $\mathrm{M}_{\mathrm{d}}$ e $\mathrm{r}_{\mathrm{p}}$-, sustenta-se aqui a validade do mecanismo indireto de transmissão da política monetária à demanda agregada. Com base nele, discute-se o mecanismo novo-keynesiano derivado do MRC.

Como vimos na seção 1.3, embora faça menção à taxa de captação dos bancos $\left(\mathrm{r}_{\mathrm{d}}\right)$, o mecanismo de transmissão da política monetária descrito por Blanchard \& Fisher (op. cit.) estabelece uma linha direta entre o nível absoluto das reservas bancárias (RE) e a oferta de crédito (Ls), não atribuindo qualquer papel relevante ao mercado monetário e, portanto, à taxa primária $\mathrm{r}_{\mathrm{p}}-$ como, aliás, enfatizam Mankiw \& Romer na citação acima. Nesse sentido, do ponto de vista mecânico, a abordagem novo-keynesiana identifica-se com um modelo simples de multiplicador bancário, apesar da sofisticação e originalidade do modelo analítico em que se apoia. A diferença em relação ao mecanismo monetarista, a que se referem Stiglitz $\&$ Weiss no trecho citado, resume-se ao comportamento dos preços envolvidos no processo - não só a taxa de juros dos empréstimos, mas também os preços do "lado real" que são supostos flexíveis no enfoque monetarista e rígidos no novokeynesiano. Uma limitação básica dos modelos de multiplicador é que eles ignoram a existência de demanda por moeda por parte dos bancos, o que implica desconsiderar a política de reservas e de administração do passivo dessas instituições como parte de suas estratégias de maximização de lucro e controle de risco. A influência desses fatores sobre a oferta de crédito fica, no máximo, implícita nesses modelos — é o caso da abordagem de Blanchard \& Fisher (1994, pp. 483 e 487), na qual o custo de captação $r_{d}$ é convenientemente identificado com a taxa de retorno esperada pelo banco $\left(\mathrm{r}_{\mathrm{b}}\right)$ - Tal procedimento obscurece passagens importantes do processo de transmissão da política monetária, particularmente quando se analisa seus efeitos na fase recessiva do ciclo.

Do ponto de vista do banco, como vimos, essa fase se caracteriza por grande desconfiança quanto à capacidade de pagamento das firmas, que se traduz pela redução da probabilidade máxima $\mathrm{P}$, utilizada em seu cálculo maximizador. Além disso, as dificuldades de liquidez das firmas tendem a fazê-las converter boa parte de suas aplicações em depósitos à vista, pressionando, assim, o custo de reservas $\left(r_{s}\right)$ e de captação de depósitos dos bancos $\left(r_{d}\right)$. Nessas condições, a tendência natural dos bancos é tentar elevar também a taxa dos empréstimos (r), de modo que, pelo menos, preserve o seu spread, dado por:

$$
\begin{aligned}
& \mathrm{s}=\left(\mathrm{r}-\mathrm{r}_{\mathrm{c}}\right) \text {,onde: } \\
& \mathrm{r}_{\mathrm{c}}=\mathrm{c}_{1} \cdot \mathrm{r}_{\mathrm{s}}+\mathrm{c}_{2} / \mathrm{r}_{\mathrm{d}},
\end{aligned}
$$

onde $c_{1}$ e $c_{2}$ representam, respectivamente, os pesos médios das reservas de terceiros (captadas no mercado interbancário) e dos depósitos do público no total de obriga-

\footnotetext{
${ }^{19}$ Para uma síntese dos efeitos das políticas fiscal e monetária segundo cada uma dessas interpretações, ver Leijonhufvud (1981a) e Branson (1979), pp. 418-429.
} 
ções dos bancos. O eventual aumento em r, porém, dificilmente virá acompanhado de aumento da oferta de crédito, exceto na estrita medida da renovação, quase que obrigatória, dos débitos não liquidados pelas firmas.

Uma expansão monetária nessas circunstâncias teria, provavelmente, o efeito de reduzir $r_{c}$, mediante o custo de reservas $r_{s}$, admitindo-se que esse último mantenha relação direta (e mais ou menos estável) com a taxa primária de juros, $\mathrm{r}_{\mathrm{p}}$ Admitindo-se também que a elasticidade-juro da demanda por moeda dos bancos seja não-desprezível na fase recessiva do ciclo - mais em função da incerteza reinante que do baixo nível da atividade econômica - a redução em $r_{p}$ e $r_{s}$, dificilmente se traduzirá em vazamento significativo da expansão monetária para a oferta de crédito. Em síntese, consideradas as variáveis do passivo e o estado de confiança do sistema bancário num ambiente recessivo, constata-se que a transmissão direta de RE (reservas) para Ls, prevista na análise de Blanchard \& Fisher (1994), não se verifica.

A despeito do efeito pouco significativo sobre a oferta de crédito, a política monetária expansiva tem um importante papel a cumprir nas fases recessivas do ciclo econômico: o de evitar que a desaceleração dos negócios se converta em crise bancária, o que, além de aprofundar a recessão, costuma ter graves consequências para a própria estrutura do sistema financeiro. Nesse sentido, pode-se dizer que o papel da política monetária é basicamente o mesmo nas fases expansiva e recessiva do ciclo econômico: o de zelar pela solidez do sistema financeiro, de modo que o capacite, tecnicamente, a cumprir sua função típica, a de intermediar e prover fundos para financiar a atividade econômica. A intervenção anticíclica propriamente dita, no sentido de reverter o quadro de deficiência de demanda que caracteriza as recessões, é mais eficazmente implementada pela política fiscal e/ou por políticas mais amplas de desenvolvimento. ${ }^{20}$

\section{CONCLUSÃO}

Este artigo analisou criticamente o modelo de racionamento de crédito (MRC) novo-keynesiano e sua relação com a abordagem dessa escola sobre o papel e o modo de operação da política monetária anticíclica. As críticas apresentadas podem ser classificadas em dois grupos: as internas ao modelo e as externas, associadas ao seu uso e implicações para a análise da política monetária.

No âmbito das críticas internas, o argumento central é de que o equilíbrio com racionamento da demanda, descrito no MRC como expressão da racionalidade dos bancos diante da assimetria de informação, é aceitável como resultado "micro" mas não macroeconômico - isto é, para um ou poucos bancos isoladamente, mas não para o mercado de crédito em seu conjunto. Para desenvolver e ilustrar esse argu-

\footnotetext{
${ }^{20}$ Sobre o papel das políticas monetária e fiscal na visão de Keynes, ver Carvalho (1995).
} 
mento, propõe-se uma análise em separado da operação do modelo nas fases expansiva e recessiva do ciclo econômico.

$\mathrm{Na}$ fase expansiva, a aceitação do MRC como resultado macroeconômico implica a aceitação de hipóteses pouco plausíveis a respeito da racionalidade e da atuação do sistema bancário na economia, quais sejam: (i) de que os bancos, normalmente, atuem como "estabilizadores automáticos" (endógenos) do ciclo expansivo; (ii) de que as expectativas e o estado de confiança das "firmas bancárias" sejam imunes aos fatores que condicionam e orientam a formação de expectativas pelas firmas não-bancárias; (iii) que bancos sejam agentes mais capazes que as demais firmas de perceberem e evitarem os riscos a que se expõem; (iv) que sejam agentes naturalmente mais cautelosos e menos propensos a riscos que as firmas não-bancárias. Quanto à fase recessiva, candidata natural à proposição de políticas anticíclicas, argumenta-se que, embora o equilíbrio com racionamento da demanda seja um resultado plausível no nível macroeconômico, ele não ocorre exatamente pelas razões alegadas no MRC, nem atua em auxílio ao mecanismo de transmissão da política. Quanto ao primeiro ponto, sustenta-se que o fator determinante do racionamento não é a rigidez da taxa de juros (como propõe o MRC), mas a reavaliação das expectativas dos bancos quanto à capacidade de pagamento das firmas. Nesse contexto, a política monetária expansiva torna-se pouco potente no sentido de estimular a expansão da oferta de crédito pelos bancos, sendo seu principal - e crucial - papel o de manter um grau de liquidez minimamente seguro no mercado interbancário, de modo que evite a degeneração de uma simples fase recessiva em crise bancária e depressão econômica.

A rejeição das hipóteses necessárias para justificar o racionamento de crédito como fenômeno macroeconômico na fase expansiva do ciclo, bem como das hipóteses do MRC como justificativa para o (plausível) racionamento na fase recessiva, implica a rejeição do modelo como base teórica para a análise do papel e do mecanismo de transmissão da política monetária. Esta é, em essência, a crítica externa dirigida ao modelo no presente texto.

Cabe ressaltar, por fim, que, embora inadequado como instrumento de análise da política monetária, o MRC é um importante instrumento teórico para justificar intervenções "verticais" (setoriais) das autoridades econômicas no mercado de crédito. Ao reconhecer a possibilidade e a racionalidade do racionamento no nível micro econômico, como resultado da assimetria de informação e dos riscos a que se expõem os bancos nas operações de crédito, o modelo demonstra a necessidade desse tipo de intervenção em áreas ou projetos cujas perspectivas de sucesso sejam de difícil avaliação. Este é, de um modo geral, o caso de projetos de infra-estrutura — em face do longo prazo de maturação e imobilização de recursos envolvido bem como de investimentos em P\& D (pesquisa e desenvolvimento tecnológico) e em setores " de ponta" - pela inexistência de uma história pregressa do setor ou produto que permita uma avaliação minimamente segura de suas perspectivas de retorno. Nesses casos, de fato, o racionamento do crédito, explicado por problemas de informação, é bastante provável. Contudo, não poderá ser removido por políticas horizontais de expansão da liquidez, mas apenas por incentivos diversos aos bancos privados e/ou pela atuação direta do setor público na provisão de fundos. 


\section{APÊNDICE A — EFEITO INCENTIVO \\ DO AUMENTO DOS JUROS}

De (7) temos que o retorno líquido esperado pelas firmas, que orienta sua demanda de crédito é:

$$
\mathrm{E}\left(\mathrm{R}_{\mathrm{i}}\right)=\mathrm{P}_{\mathrm{i}}\left[\mathrm{S}_{\mathrm{i}}-(1+\mathrm{r}) \cdot \mathrm{B}\right]
$$

Dessa forma, diante do aumento em $r$, as firmas que se manterão como demandantes de empréstimos são as de maior $S_{\mathrm{i}}$. Mas, ae (4), temos:

$$
\mathrm{E}(\mathrm{RB})=\mathrm{P}_{\mathrm{i}} \mathrm{S}_{\mathrm{i}}+\left(1-\mathrm{P}_{\mathrm{i}}\right) \mathrm{F}
$$

Considerando dois projetos, $\mathrm{i}=1$ e $\mathrm{i}=2$, e dada a condição

$$
\mathrm{E}\left(\mathrm{RB}_{1}\right)=\mathrm{E}\left(\mathrm{RB}_{2}\right)=\mathrm{E}(\mathrm{RB})
$$

podemos escrever:

$$
\begin{aligned}
& \mathrm{P}_{1} \mathrm{~S}_{1}+\left(1-\mathrm{P}_{1}\right) \mathrm{F}=\mathrm{P}_{2} \mathrm{~S}_{2}+\left(1-\mathrm{P}_{2}\right) \mathrm{F} \therefore \\
& \mathrm{P}_{1} \mathrm{~S}_{1}-\mathrm{P}_{2} \mathrm{~S}_{2}=\left(\mathrm{P}_{1}-\mathrm{P}_{2}\right) \mathrm{F}
\end{aligned}
$$

Admitindo-se $\mathrm{S}_{2}>\mathrm{S}_{1}$ e sabendo que (por definição) $\mathrm{F}<\mathrm{S}_{\mathrm{i}}$, façamos:

$$
\begin{aligned}
& \mathrm{S}_{1}=\mathrm{x} . \mathrm{S}_{2}, 0<\mathrm{X}<1 \\
& \mathrm{~F}=\mathrm{y} . \mathrm{S}_{2}, 0<\mathrm{y}<\mathrm{x}<1 \quad \therefore \\
& \mathrm{P}_{1} \text { x. } \mathrm{S}_{2}-\mathrm{P}_{2} \mathrm{~S}_{2}=\left(\mathrm{P}_{1}-\mathrm{P}_{2}\right) \text { y. } \mathrm{S}_{2} \therefore \\
& \text { x. } \mathrm{P}_{1}-\mathrm{P}_{2}=\mathrm{y} \cdot \mathrm{P}_{1}-\mathrm{y} \cdot \mathrm{P}_{2} \therefore \\
& (x-y) \cdot P_{1}=(1-y) \cdot P_{2} \\
& \text { Como } 0<\mathrm{y}<\mathrm{x}<1 \text {, então }(\mathrm{x}-\mathrm{y})<(1-\mathrm{y}) \text {. Portanto: } \\
& (x-y) \cdot P_{1}=(1-y) \cdot P_{2} \Leftrightarrow P_{2}<P_{1}
\end{aligned}
$$

\section{APÊNDICE B - AUSÊNCIA DO EFEITO INCENTIVO DIANTE DO AUMENTO DE E(RB)}

Demonstra-se, assim, que, com $\mathrm{E}(\mathrm{RB})$ dado, os projetos de maior retorno bruto esperado em caso de sucesso (o projeto 2 , no caso) são os de menor probabilidade de sucesso.

Seja $\mathrm{E}\left(\mathrm{RB}_{2}\right)>\mathrm{E}\left(\mathrm{RB}_{1}\right)$, onde os índices 1 e 2 denotam, respectivamente, os períodos anterior e posterior ao aumento em $\mathrm{r}$. De (4) podemos escrever:

$$
\begin{aligned}
& \left.\left.\mathrm{P}_{2} \mathrm{~S}_{2}+\right) 1-\mathrm{P}_{2}\right) \mathrm{F}>\mathrm{P}_{1} \mathrm{~S}_{1}+\left(1-\mathrm{P}_{1}\right) \mathrm{F} \therefore \\
& \mathrm{P}_{2} \mathrm{~S}_{2}-\mathrm{P}_{1} \mathrm{~S}_{1}>\left(\mathrm{P}_{2}-\mathrm{P}_{1}\right) \mathrm{F}
\end{aligned}
$$


A partir das mesmas transformações utilizadas no Apêndice A para os termos S1e F, obtém-se:

$$
(1-y) \cdot P_{2}>(x-y) \cdot P_{1}
$$

Como $(1-\mathrm{y})$ é necessariamente maior que $(\mathrm{x}-\mathrm{y})$, a condição acima se verifica mesmo com $\mathrm{P}_{2}=\mathrm{P}_{1}$. Demonstra-se, assim, que, se admitirmos $\mathrm{E}(\mathrm{RB})$ em crescimento, o efeito incentivo apontado por Stiglitz \& Weiss (1989) não é uma implicação do aumento em r, podendo-se observar, após o aumento, a atração de projetos de investimento pelo banco com as mesmas probabilidades de sucesso - e mesmos riscos - que os de antes.

\section{REFERÊNCIAS}

BALTENSPERGER, E. (1980) “Alternative Approaches to the Theory of Banking Firm” Journal of Monetary Economics, n. 8, January.

BEZERRA, R. S. (1994) “A Teoria Pós-Keynesiana da Firma Bancária”. Revista Archè, Ano III, nº 7, pp. 109-35.

BLANCHARD, O. \& FISHER, S. (1994) Lectures on Macroeconomics. London: MIT Press.

BRANSON, W. (1979) Macroeconomia: Teoria e Política. Lisboa: Fundação Calouste Gulbenkian.

CARVALHO, F. J. Cardim de (1995) "Economic Policies for Monetary Economics”, Texto para Discussão IE-UFRJ, $\mathrm{n}^{\circ}$ 331, fevereiro.

CLOWER, R. (1965) “The Keynesian Counter-Revolution: A Theoretical Appraisal”, in F. H. HAHN e F. P. R. BRECHLING (eds.), The Theory of Interest Rates. London: Macmillan.

FRIEDMAN, M. (1956) “The Quantity Theory of Money: a Restatement” in M. FRIEDMAN, Studies in the Quantity Theory of Money. University of Chicago Press.

FRIEDMAN, M. (1959) “The Demand for Money: some theoretical and empirical results.” Journal of Political Economy, vol. 67, no 4, pp. 327-51, August.

FRIEDMAN, M. (1968) "The Role of Monetary Policy" in American Economic Review, March.

FRIEDMAN, M. (1970) "A Theoretical Framework for Monetary Analysis” in Journal of Political Economy, March-April.

FRIEDMAN, M. (1976) "Inflação e Desemprego: a novidade da dimensão política", in Literatura Econômica, 7 (3), outubro, 1985.

GOLDFELD, S. M. (1973) “The Demand for Money Revisited”. Brookings Papers on Economic Activity, Vol. 3.

HICKS, J. (1983) “O Sr. Keynes e os Clássicos: uma sugestão de interpretação”, in Literatura Econômica, 5(2), pp.139-58.

KEYNES, J. M. (1985) A Teoria Geral do Emprego, do Juro e da Moeda. São Paulo: Nova Cultural.

KEYNES, J. M. (1979) A Treatise on Money, Vol. 2. London: Macmillan.

LAIDLER, D. E. W. (1977) The Demand for Money: theories and evidence. New York: Dun-Donnelley Publishing Corp.

LEIJONHUFVUD, A. (1968) On Keynesian Economics and the Economics of Keynes: a study in monetary theory. London: Oxford University Press.

LEIJONHUFVUD, A. (1981a) “ Keynes and the Keynesians: a Suggested Interpretation “, in A. LEIJONHUFVUD, Information and Coordination, Oxford University Press.

LEIJONIIUFVUD, A. (1981b) “The Wicksell Connection”, in A. LEIJONHUFVU, Information and Coordination, Oxford University Press.

LUCAS, R. (1981) "Understanding Business Cycles”, in R. LUCAS, Studies in Business Cycle Theory. Cambridge: MIT Press.

LUCAS, R. e SARGENT, T. (1981) “After Keynesian Macroeconomics”, in R. R. LUCAS e T. SAR- 
GENT (eds.), Rational Expectations and Econometric Practice. Vol. 1. Minneapolis: University of Minnesota Press.

MACHADO, P. C. (1995) Uma Crítica Pós-Keynesiana à Concepção Ortodoxa de Firma Bancária. Tese de Doutorado. Rio de Janeiro: IE/UFRJ.

MALINVAUD, E. (1977) The Theory of Unemployment considered. Oxford: Basil Blackwell.

MANKIW, G. (1990) "A Quick Refresher Course in Macroeconomics". Journal of Economic Literature, vol. XXVIII, December.

MANKIW, G. \& ROMER, D., ed. (1989) New Keynesian Economics. Cambridge: MIT Press.

MINSKY, H. P. (1982) Can It Happen Again? Armonk: M.E. Sharpe.

MINSKY, H. P. (1986) Stabilizing an Unstable Economy. New Haven, Yale University Press.

SANTOMERO, A. (1984) "Modelling the Banking Firm”. Journal of Money, Credit and Banking, vol. $16, n^{\circ} 4$, November.

SARGENT, T. (1981) "A Classical Macroeconomic Model for the United States”, in R. LUCAS e T. SARGENT (eds.), Rational Expectations and Econometric Practice. Vol. 1. Minneapolis: University of Minnesota Press.

SARCENT, T. e WALLACE, N. (1981) "Rational Expectations and the Theory of Economic Policy", in R. LUCAS e T. SARGENT (eds.), Rational Expectations and Econometric Practice. Vol. 1. Minneapolis: University of Minnesota Press.

SIMONSEN, M. H. (1983) Dinâmica Macroeconômica. São Paulo, McGraw-Hill.

STIGLITZ, J. e WEISS, A. (1989) "Credit Rationing in Markets with Imperfect Information", in G. MANKIW e D. ROMER (eds.), New Keynesian Economics. Cambridge: MIT Press. Originalmente publicado em American Economic Review, 71, June, 1981, pp. 353-376.

TRICHES, D. (1992) Demanda por Moeda no Brasil e a Causalidade entre Variáveis Monetárias e a Taxa de Inflação: 1972/87. $16^{\circ}$ Prêmio BNDES de Economia. Rio de Janeiro: BNDES.

WICKSELL, K. (1985) Lições de Economia Política. São Paulo: Nova Cultural. 